\title{
O ESTUDO DO DIREITO E O MÉTODO DAS CIÊNCIAS
}

\author{
THE STUDY OF LAW AND THE SCIENTIFIC METHOD
}

Fernando Curi Peres*

\begin{abstract}
Resumo:
Algumas Faculdades de Direito utilizam, erroneamente, o nome de Introdução à Ciência do Direito aos alunos do primeiro ano do curso, quando estes vão começar seus estudos de Direito. A maioria dos alunos nunca foi exposta ao método das ciências e terminam seu curso sem saber sobre ele. $\mathrm{O}$ artigo argumenta que, à semelhança de estudantes comuns de Direito, estes devem estar familiarizados com estatísticas e o método das ciências para garantir que suas ações baseiem-se em ação realista, em vez de propostas e percepções idealistas.

Palavras-chave: Método científico. Direito e ciência. Formação jurídica.

Abstract:

Some Brazilian schools of Law wrongly name Introduction to the Science of Law the first core course students take when beginning their studies of Law. Most students have never been exposed to the method of sciences and finish their course without knowing about it. The article argues that, similarly to Common Law students, they should be familiarized with Statistics and the method of sciences to ensure that they base their action on realistic instead of idealistic proposals and perceptions.
\end{abstract}

Keywords: Method of science. Science and Law. Law studies curricula.

\section{Introdução}

Existem inúmeras formas de conhecimento adquiridos ou construídos pelos homens. Elas vão desde a existência de fenômenos físicos que são percebidos como regulares, recorrentes ou cíclicos, passando por associações que a mente humana condiciona, como descrito por Pavlov, pelo resultado da aplicação do chamado método científico, até meras criações associativas que resultam de processos idealizados pela mente humana. Além dessas, talvez uma entre as mais marcantes formas de conhecimento, medida por sua importância na vida das pessoas, é aquele derivado de verdades que as pessoas acreditam lhes ter sido reveladas por espíritos ou entes superiores. Condições ambientais diversas, influenciadas ou não pelas variações genéticas entre as pessoas, produzem culturas diferentes que apresentam, correspondentemente, valores éticos ou morais que condicionam os comportamentos dos grupos humanos.

\footnotetext{
* Mestre em Direito Civil pela Faculdade de Direito da USP; PH.D. pela The Ohio State University; Professor Titular Senior da área de Economia e Administração da ESALQ/USP e Professor Titular da Faculdade Autônoma de Direito de São Paulo - FADISP.
} 
A pacificação dos indivíduos na sua convivência dentro dos grupos e na correspondente relação entre os diversos grupos é o objeto maior do Direito. Desta forma a importante área do conhecimento humano que compreende o vastíssimo campo da normatização e da sua aplicação pelas sociedades para impor regras de comportamento social aos diversos agrupamentos humanos é fortemente influenciada pela contingência cultural e pelos valores éticos ou morais das diferentes comunidades e nos diferentes períodos, os quais resultam de alguma forma de interação dos conhecimentos das pessoas que compõe os agrupamentos.

Muitas conceituadas escolas do país utilizam o nome de Introdução à Ciência do Direito na denominação da importante disciplina introdutória ao estudo do Direito. O fato decorre, possivelmente, do mau uso do conceito de ciência, ou do desconhecimento do seu método, com o consequente enquadramento errado. Pelo menos três alternativas precisam ser consideradas nas implicações das correspondentes visões: (i) o problema pode ser simplesmente semântico, derivado de definições alternativas de ciência; (ii) pode acontecer por um entendimento errôneo sobre o método das ciências; ou, ainda, (iii) por um desejo pouco explicitado de enquadrar o Direito na prestigiosa categoria das ciências. Neste trabalho não será tratado deste terceiro item, uma vez que, de fato, o objeto do estudo do Direito é tão ou mais importante para a vida das pessoas do que os conhecimentos tratados por qualquer disciplina na qual se dividem as ciências.

O eixo fundamental da argumentação deste trabalho é a defesa da exigência prática de conhecimento do método das ciências pelos aplicadores do Direito, uma vez que importantes resultados da aplicação do método não podem ser ignorados pelos juristas, especialmente na acomodação das normas jurídicas a limitações ou, mesmo, imposições do mundo físico. Devido a deficiências de conhecimentos sobre "o que são os fenômenos do mundo", objeto das ciências, alguns aplicadores do Direito imaginam, ou constroem idealmente, organizações ou situações de convivência nunca alcançadas no mundo real devido ao seu irrealismo potencial. A tese fundamental do trabalho é a de que as construções do "mundo do que deve ser", principal seara do jurista, devem estar alicerçadas no conhecimento científico humano o qual tenta entender o "mundo do que é", objetivo máximo que o método das ciências pode aspirar com sua contribuição. À consideração de que as leis são feitas pelo Legislativo é preciso reconhecer o perigo daquela construção idealista acontecer mesmo com a separação formal entre os poderes, uma vez que é o Poder Judiciário que interpreta e aplica as leis escritas pelo Legislativo. ${ }^{1}$

\footnotetext{
No entanto, como afirma AZEVEDO, P. F. de "Como já em certo sentido escrevemos alhures, é no plano dinâmico da interpretação e aplicação do Direito que se desvelam as suas grandes questões. São os práticos - o advogado, o juiz, o consultor jurídico, o representante do Ministério Público - que, buscando solução aos casos concretos, deparam com a possível inadequação das normas jurídicas aos fatos a que são prepostas". In AZEVEDO, P. F. de "Introdução" de Fuller, Lon L. O caso dos exploradores de cavernas. Tradução e
} 
$\mathrm{O}$ artigo apresenta quatro partes, além desta introdução. A segunda parte apresenta o método universal de análise como utilizado pelas ciências; no seu subitem são mostrados dois exemplos de usos do método. A terceira parte trata de algumas considerações relevantes para o ensino do Direito no desenho da grade curricular mínima exigida dos seus alunos. Finalmente, a quarta e última parte tece alguns comentários a título de conclusão.

\section{O Método das Ciências}

A libertação da capacidade analítica dos agrupamentos humanos - da razão - dos europeus do monopólio de igrejas ocorrido a partir dos séculos XIX, resultado de contestações internas e do renascimento do pensamento grego, permitiu o desenvolvimento do método cientifico de aumento do conhecimento humano. O método das ciências, inicialmente proposto por Francis Bacon e Renè Descartes, foi brilhantemente aplicado pelos gênios de Isaac Newton e Galileu Galilei a visões teóricas e práticas, e consequentemente realistas, de fenômenos do mundo físico. A síntese do método científico, tal como conhecido modernamente, começou então e tem se aperfeiçoado constantemente, estando sua denominação atual geralmente restrita e aceita como aquela que usa encadeamentos lógicos na construção das suas teorias e necessariamente testa as hipóteses delas derivadas com os instrumentos da estatística.

O método das ciências pode ser sistematicamente sintetizado, para fins de apresentação didática, em 5 (cinco) fases: (i) a explicitação do fenômeno ou evento que se quer conhecer; (ii) o desenvolvimento, ou utilização de um modelo já desenvolvido - teoria - que explique o fenômeno ou evento de forma genérica; (iii) a partir do modelo teórico utilizado são criadas ou identificadas hipóteses relevantes - que podem ser negadas - para serem testadas com os dados do mundo, tanto de experimentos especialmente conduzidos quanto de situações reais observadas; (iv) o teste estatístico das hipóteses; e (v) o fortalecimento ou enfraquecimento da convicção sobre a capacidade do modelo ou da teoria proposta na explicação do fenômeno ou evento estudado.

A Figura 1 apresenta, graficamente, as cinco fases do método científico. A generalidade do seu método, aliado à tremenda utilidade que a humanidade tem auferido com seu uso, garante o imenso prestígio das ciências entre os povos, especialmente entre aqueles com consideráveis estoques educacionais. Desta forma, algumas pessoas de outras áreas do conhecimento que não conseguem ou não querem utilizar o método em suas indagações, também chamam de ciência ao seu comportamento analítico. É o caso

Introdução de Plauto Faraco de Azevedo. Porto Alegre: Sergio Antonio Fabris Editor, 1976. p. XII. 
da Psicoanálise e do Direito, que são importantes formas de conhecimento, embora nãocientíficos.

\section{O Método da Ciência}
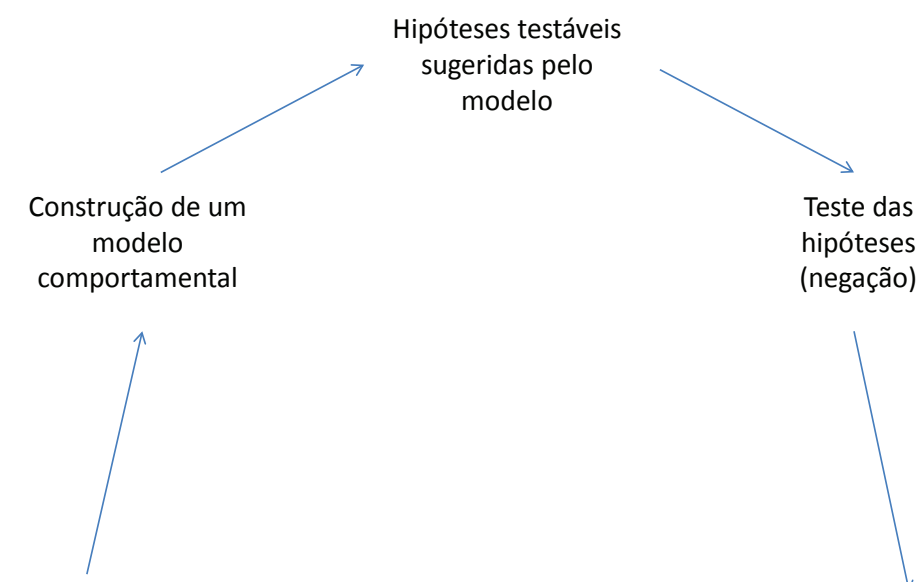

Fenômeno que se quer explicar

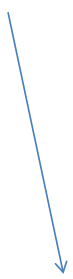

Aumento no conhecimento

Figura 1. Fases do Método das Ciências

$\mathrm{Na}$ fase inicial do uso do método científico é necessário explicitar, claramente, o fenômeno ou evento que se quer explicar ou conhecer. Aqui existe uma importante distinção entre as ciências e outras formas de conhecimento: o método da ciência é útil para explicar como é o mundo físico; ele não serve para indicar como as coisas do mundo devem ser. Algumas áreas do conhecimento humano tratam especificamente do que deve ser o comportamento humano no seu relacionamento econômico, político e social. É o caso dos juristas. Embora não utilizem o método das ciências nas suas análises em geral eles podem, e frequentemente o fazem em certos países, basear suas proposições em conhecimentos desenvolvidos pelas ciências; de fato, este alicerçamento de suas proposições deveria acontecer frequentemente, como forma de garantir o seu realismo ou a eficiência ou eficácia na indução dos comportamentos socialmente desejados.

A construção ou utilização de um modelo teórico que explica o fenômeno é a parte mais importante do método da ciência. Toda divisão das ciências em disciplinas ou ramos é feita para permitir a síntese de uma linguagem que facilite ou permita a transmissão dos conceitos que fundamentam seu conhecimento e que gerem hipóteses para 
serem testadas. A Física, a Química, a Biologia, a Psicologia, a Economia, a Sociologia e outras áreas das ciências desenvolvem modelos - teorias - específicos que são aceitos por números crescentes de cientistas até que novos testes ou teorias mais abrangentes sejam desenvolvidos e forcem a reformulação ou abandono daquelas. O Padre Henrique Vaz, importante filósofo católico brasileiro, dizia que o teórico era o indivíduo da Grécia Antiga que subia nos morros para ter uma visão completa dos desfiles, em vez de apreciar a passagem de batalhão por batalhão. A figura mostra uma importante dimensão do termo teoria: ela requer uma integração orgânica das partes que a compõem. Assim, a um conjunto de hipóteses já testadas ou a serem testadas, que permitem gerar um sistema orgânico, dá-se o nome de teoria. Esta é a maneira de criar teorias a partir da organização de eventos observados, com no uso do chamado método indutivo. É a maneira fundamental dos cientistas criarem teorias embora, definitivamente, não seja a única.

Antes do desenvolvimento e explicitação do método científico o conhecimento humano desenvolveu um grande número de artefatos e procedimentos que melhoraram a vida das pessoas. É claro que é útil saber como funcionam as ondas magnéticas ou de rádio para se construir melhores aparelhos de comunicação, mas, de fato, excelentes instrumentos podem ser construídos sem o conhecimento profundo de como as coisas são ou se comportam no mundo. Pode-se, por exemplo, condicionar reflexos associativos ao fato do consumo de determinada erva ou parte de uma planta melhorar o estado de saúde dos indivíduos que apresentam os sintomas de escorbuto sem que se saiba nada sobre a existência de uma substância chamada vitamina C. Certos tipos de conhecimento podem ser muito úteis embora não resultem da aplicação do método das ciências. Assim, no desenvolvimento ou escolha da teoria que se utiliza para explicar o fenômeno ou evento estudado podem ser utilizadas formas de conhecimento não geradas pelo próprio método científico. Novos produtos, maneiras de atuação e criações continuaram e continuarão a surgir no mundo humano. No entanto, o uso sistemático do chamado método das ciências é tão mais importante no surgimento dessas novidades que inúmeros pensadores têm denominado nosso tempo de Era do Conhecimento, exatamente porque desde a Segunda Guerra Mundial os países e empresas de maior sucesso utilizam, sistemática e formalmente, o método das ciências nos processos de criação de novos conhecimentos e produtos. ${ }^{2}$

Quando se considera o sentido em que é definida a ciência - aumento do conhecimento das coisas do mundo que resulta da aplicação do método descrito - pode-se excluir a própria Lógica, ou a Matemática como um caso particular de Lógica, do que se denomina de ciência. A Matemática tem sido chamada de "a linguagem da ciência”. Ela é

Stehr, Nico. Knowledge Societies. London: Sage Publications, 1994. 
uma importantíssima construção do gênio humano e seu uso generalizado tem permitido às ciências verificar a consistência interna dos modelos propostos - ou das teorias - e dos sofisticados instrumentais analíticos da estatística utilizados para testar a aderência dos dados do mundo real às hipóteses sugeridas pelas teorias ou pela intuição humana. No entanto, a Matemática não é uma ciência, embora seja uma importantíssima linguagem usada por elas. Não é uma ciência porque para se acrescentar novos conhecimentos ao conjunto de seus saberes não se recorre ao método científico. É por essa razão que na Matemática pode-se provar definitivamente uma proposição, o que não é possível com o método científico. Não se prova que José é filho de João mesmo com resultados positivos dos testes de DNA. O teste de DNA pode, no máximo, indicar uma altíssima probabilidade de José ser filho de João, mas não pode provar isto, pelo menos com o método atual das ciências.

No prefácio da tradução do festejado livro do professor Lon L. Fuller da Harvard Law School, intitulado O Caso dos Exploradores de Cavernas $^{3}$ o jurista e tradutor Plauto Faraco de Azevedo cita Perelman e afirma que:

... há mesmo formas de raciocínio mais elevadas, que não constituem propriamente cálculos nem tampouco podem ser formuladas como 'demonstrações', 'pertencendo, em contrapartida, à argumentação'. E é esta 'precisamente' o tipo de raciocínio empregado pelo jurista... A tradição cartesiana, que busca acima de tudo a evidência, desdenha qualquer proposição que não possua o caráter do óbvio, do indiscutível, do exato, do preciso. Todavia, esta concepção logicista ou matematizante do pensamento é demasiadamente estreita, pois não abrange grande quantidade de raciocínios, que não têm e nem podem ter forma demonstrativa ... Mas sucede que a própria índole da deliberação e da argumentação se opõem à evidência e à necessidade absoluta; porque não se delibera nos casos em que a solução tem caráter contra a evidência. A argumentação tem seu sentido verossímil, no plausível e no provável, escapando estes à certeza de cálculo exato de que resulte uma única solução justificável em termos absolutos... (AZEVEDO, Plauto F., ${ }^{4}$ p. XIII)

\footnotetext{
3 AZEVEDO, P. F. de in "Introdução" de Fuller, Lon L. O Caso dos Exploradores de Cavernas. Tradução e Introdução de Plauto Faraco de Azevedo. Porto Alegre: Sergio Antonio Fabris Editor, 1976 citando Perelman, Chaim. De La justicia Trad. De Ricardo Guerra. Pref. De Luis Recasens Siches. México, Unversidad Nacional Autónoma de México, 1964, p. II-III.

4 AZEVEDO, P. F. de in "Introdução" de Fuller, Lon L. O caso dos exploradores de cavernas. Tradução e Introdução de Plauto Faraco de Azevedo. Porto Alegre: Sergio Antonio Fabris Editor, 1976.
} 
Ora, existem muitas lógicas e a Matemática é um caso especial delas. Podese, também, usar a denominação genérica de Lógica aristotélica (que o citado Autor chama de pensamento cartesiano) com a qual a própria Matemática é consistente. Na ausência de um processo lógico de raciocínio, incorre-se em situações falaciosas. O uso implícito da Lógica aristotélica assegura a ausência de raciocínios falaciosos cuja presença invalida, nas ciências, a teoria que está sendo utilizada ou proposta. Em análises que envolvem distâncias temporais estremas e em outros casos específicos o método das ciências permite teorias explicitadas com o auxílio das chamadas Lógica fuzzy, Lógica dialética ou outras. O importante é que algum tipo de lógica precisa ser seguido nas argumentações que levem à escolha da teoria e à derivação da(s) hipótese(s) a ser(em) testada(s). Sofismar pode ser uma atitude aceita em argumentações dos advogados no afã de defender os direitos de um réu; porem ela não contribui em nada para o desenvolvimento de raciocínios que levem ao aprimoramento do pensamento jurídico e na preparação de novos aplicadores do Direito!

O uso da lógica é fundamental para a identificação de hipóteses derivadas de teorias que se quer testar. Uma vez escolhida a hipótese, o passo seguinte é seu testefalseabilidade - que permite comparar previsões com dados coletados em experimentos ou com observações de eventos efetivamente ocorridos. No processo, utiliza-se de instrumental estatístico que nada mais faz do que associar probabilidades de que os dados observados tenham ocorrido puramente ao acaso e não devido à causa implícita na hipótese. Se a ocorrência do fenômeno se desviou significativamente do que ocorreria em situações puramente aleatórias não se rejeita a hipótese. Caso contrário, a teoria é enfraquecida com a evidência que contraria suas implicações. A não-negação das hipóteses derivadas de uma explicação generalizada do fenômeno fortalece a crença das pessoas na validade desta teoria. Assim, se constrói o conhecimento científico!

\section{A. Um exemplo do uso do método das ciências}

Um exemplo pode ajudar no entendimento de como funciona o método das ciências. Considere a viagem exploratória (fictícia) feita no final do século XIX quando saíram da Nova Zelândia quatro navios com jovens marinheiros que pretendiam explorar o Polo Sul, até então uma região desconhecida do globo terrestre. Cada navio levava 25 marinheiros, totalizando 100 jovens exploradores. Pesquisadores de uma instituição em Auckland resolveram testar uma hipótese para fortalecer uma teoria recentemente explicitada. Ela tratava do papel das vitaminas na nutrição humana, especialmente na prevenção de certas doenças. Os cientistas queriam testar a hipótese de que a ausência prolongada (seis ou mais semanas) de Acido Ascórbico na alimentação humana causaria a doença conhecida como escorbuto. A viagem exploratória deveria durar de dez a doze semanas e durou, efetivamente, quase quatorze semanas. 
Nos quatro grupos, todos receberam uma ração básica diária correspondente a uma porção de pão (250 gr.), carne seca e/ou defumada (300 gr.), uma porção de queijo (100 gr.), cerveja (750 ml) e água à vontade. Além da ração básica, cinquenta marinheiros escolhidos aleatoriamente, treze em cada um de dois grupos e doze em cada um dos outros dois, receberam $75 \mathrm{ml}$ de suco de limão por dia durante todo o período; os demais cinquenta marinheiros, doze em cada um de dois grupos e treze em cada um dos outros dois, só se alimentaram da ração básica durante as quase quatorze semanas da viagem. Ao final da viagem quarenta e dois marinheiros tinham desenvolvido os sintomas de escorbuto: 37 nos grupos que não receberam o suco de limão $(9,10,8$ e 10 , respectivamente em cada subgrupo de 25) e 5 nos subgrupos que receberam o suco de limão $(1,2,1$ e 1 , respectivamente).

Os estatísticos garantiram que com menos de $1 \%$ de chance de erro em termos de sua probabilidade não se pode rejeitar a hipótese de que o escorbuto teria sido causado pela ausência de ácido ascórbico, ou de alguma outra substância presente no suco do limão, na alimentação dos sorteados. A partir de então, foi fortalecida a teoria que indicava que algumas doenças podem ser causadas por deficiências alimentares, especialmente as vitaminas, entre as quais estaria o ácido ascórbico. Posteriormente inúmeros experimentos confirmaram a relação estudada e a ciência considera a teoria como verdadeira, pelo menos até que novas evidências (dados) indiquem hipóteses e teorias alternativas mais abrangentes que expliquem os resultados experimentais já observados e outros.

De forma semelhante ao experimento relatado, as teorias econômicas, sociológicas, psicológicas e outras das chamadas ciências sociais são fortalecidas pelos testes das hipóteses delas derivadas. O instrumental estatístico necessário é, em geral, mais complexo, já que muitos dados precisam ser analisados a partir de observações da vida das pessoas e instituições em vez de resultados de experimentos. Isto porque a montagem de experimentos é muito difícil, ou mesmo impossível, em muitos casos; a maioria das inferências tem que ser feitas a partir de situações efetivamente vividas, o que dificulta sobremaneira o teste. No entanto, o gênio criativo e a formação lógica dos cientistas têm permitido o desenvolvimento de instrumental analítico que assegura a possibilidade de testes, como os feitos com resultados de experimentos especialmente desenhados para permitir a falseabilidade de hipóteses.

Muitos trabalhos científicos tratam da consistência interna dos encadeamentos existentes nas teorias. Neste caso, as considerações ou análises se baseiam nos fundamentos lógicos dos modelos comportamentais - teorias - propostos. Outros partem de certos comportamentos ou pressuposições considerados válidos e derivam resultados que necessariamente fluem deles. É o caso, por exemplo, da procura de um critério social de escolha entre dois estados quaisquer da natureza a partir dos critérios 
de escolha das pessoas que compõe uma comunidade. O critério social precisa ser geral e aplicável a qualquer situação possível. De fato, trata-se de identificar um critério social de escolha, com características constitucionais de generalidade, a partir de valores ou critérios dos indivíduos que compõem aquela nação.

O problema da escolha do critério social a partir dos critérios individuais foi enfrentado, entre muitos outros, por Kennedy Arrow e seu trabalho gerou um resultado interessante. Primeiro, ele identificou o que julgou serem valores básicos das pessoas das sociedades ocidentais. Sua escolha diz que esses valores incluem: (i) a racionalidade básica do comportamento humano, expresso por sua capacidade de, entre quaisquer três estados da natureza A, B e C, as pessoas serem sempre capazes de escolher (mostrar sua preferência, P) se preferem A a B ou B a A ou ambos, simbolicamente descritos como APB, ou BPA ou AIB (onde I significa indiferença). Ainda, se APB e se BPC então, necessariamente, APC, ou as pessoas tem comportamento transitivo nas suas escolhas; (ii) se, numa população qualquer, um subgrupo de seus indivíduos prefere A a B (APB) e se apesar deste subgrupo o critério social for tal que BPA, então B tem que continuar sendo preferível a A pelo critério social se um ou mais membros daquele subgrupo mudar sua preferência para BPA; (iii) na escolha pela comunidade entre os estados da natureza A e B quaisquer o critério social tem que ser tal que a existência ou não de alternativas $\mathrm{C}$ ou $\mathrm{D}$ não pode altera-lo. Isto equivale à afirmação de que na escolha pela sociedade entre os estados da natureza $\mathrm{A}$ e $\mathrm{B}$, a posição do estado $\mathrm{C}$ não interessa. $\mathrm{C}$ é uma alternativa irrelevante; (iv) sempre que houver unanimidade nas preferências individuais entre A e B o critério social tem que refletir esta unanimidade de tal forma que se para todos APB, então o critério social tem que ser APB; e, finalmente, (v) não pode haver ditadura, ou o critério de um indivíduo não pode prevalecer sempre sobre o critério dos demais membros da comunidade. Dito de outra forma, o critério social não pode ser somente baseado no critério de um indivíduo, que seria um ditador. Estas cinco condições foram impostas por Arrow como aspirações fundamentais dos habitantes do mundo ocidental.

Arrow usou a lógica Aristotélica - derivada dos chamados silogismos utilizando uma simbolização formal e conseguiu demonstrar um importante teorema que tem tido grandes impactos nas ciências políticas, econômicas e outras. É o chamado "teorema da impossibilidade" de Arrow. Segundo este teorema é impossível existir um critério social de escolha que satisfaça às cinco condições de preferências individuais identificadas por ele. O trabalho encontra-se descrito no seu livro intitulado Social Choice and Individual Values ${ }^{5}$ com as considerações que ele usa para justificar sua escolha das cinco pressuposições. É claro que a escolha dos valores individuais identificados pelo

ARROW, K. Social choice and individual values. $2^{\text {nd }}$ ed. London: Yale University Press, 1963. 
autor pode ser discutida e não ser aceita por muitos pesquisadores. Pode-se, por outro lado testar, por meio de pesquisas especialmente desenhadas para este fim, se as populações realmente as desejam. Algumas daquelas condições já foram exaustivamente testadas, como a primeira que trata da racionalidade da escolha dos indivíduos. O resultado da aplicação da lógica não tem sido discutido mais; no entanto, até aqui é um simples exercício de lógica. Faltam testes para que as condições possam ser aceitas como valores individuais das populações ocidentais, completando o método das ciências.

\section{Algumas implicações}

Como o uso do método descrito tem sido a forma efetiva de se aumentar o conhecimento das ciências e como os juristas não o utilizam em geral seria útil averiguar se seria desejável que estes profissionais tivessem alguma familiaridade com aquele método. Como reconhece F. Genny, o jurista às vezes usa o método das ciências quando, por exemplo, investiga a eficácia ou eficiência de determinada norma jurídica. ${ }^{6}$ Neste caso é perfeitamente possível, de fato é desejável, utilizar o método descrito. Mais importante ainda, é o fato de alguns pesquisadores utilizarem sistematicamente o método das ciências e terem demonstrado que as leis no sistema do Common Law têm sido criadas de acordo com um critério socialmente aceito de aumentar a riqueza da sociedade. ${ }^{7}$ Existe, no entanto, uma razão mais importante que justificaria o conhecimento do método das ciências pelos juristas brasileiros.

A globalização - maior interação cultural, política e econômica, devido, principalmente, à revolução nas comunicações, entre as nações do mundo - é um fenômeno que veio para ficar. Embora seus benefícios não sejam percebidos igualmente por todos os povos, parece que há consenso quanto à irreversibilidade do processo. As jurisdições dos diferentes sistemas legais perde, a cada dia, sua dimensão territorial em favor da internacionalização. Os Operadores do Direito do Brasil terão, consequentemente, que interagir com outros sistemas legais e seus juristas no processo de extensão dos efeitos pacificadores do Direito às relações entre as diferentes nações e entre suas populações. Ora, o diálogo acontecerá, necessariamente, utilizando-se de raciocínios lógicos e do método das ciências como seu eixo analítico.

Qual a vantagem do diálogo entre os diferentes sistemas jurídicos acontecer orientados por raciocínios lógicos e fundados em resultados das ciências? Eles resultam em maior realismo de suas proposições, calcadas em seu alicerçamento em resultados

\footnotetext{
6 GENY, Francois. Science et technique en droit prive positif: nouvelle contribution a la critique de la methode 1922 [Fac Direito] 340.13 G295s 1922 v.1 DCV (Monografia).

7 POSNER, R.A. The economics of justice. Cambridge: Harvard University Press, 1983.
} 
derivados da aplicação do método das ciências. Deve-se notar, para fortalecer esta última afirmação, que o método das ciências como descrito neste trabalho é internacionalmente reconhecido e utilizado por quase todos os indivíduos e instituições que fazem pesquisa científica no mundo. A distinção entre a denominação das ciências e outros métodos analíticos utilizados por pensadores mais ambiciosos, no sentido de poder também responder as questões normativas sobre qual deve ser o comportamento das pessoas, pode ser mostrada no texto de F. GENY. ${ }^{8}$

Et, quando on embrasse l'ensemble des disciplines sociales sous 1'expression - alors quelque peu imprécise - de "science", c'est à cette double direction qu'on doit, à mon sens, rapporter la distinction des sciences descriptives ou explicatives et dês sciences normative; distinction, qui ne traduit qu'une diversité de tendances, et qui, pour rester juste, demande à être appliquée avec autant de sobriété que de souplesse. (F. Geny, p. 64).

Embora denominando ambas de ciências, o autor distingue a normativa da descritiva ou explicativa. Modernamente o termo ciência é utilizado somente ao tipo de conhecimento que usa o método descrito como o da ciência, o qual é chamado no texto de Geny de ciência descritiva ou explicativa.

Como acontece nos países que usam o sistema conhecido como Common Law é preciso considerar a possibilidade da exigência, na formação dos Operadores do Direito no Brasil, de conhecimentos rigorosos sobre o método das ciências. De fato, naqueles países é pré-requisito para a formação jurídica dos aplicadores da lei ter cursado quatro anos em escolas de terceiro grau (colleges) e que tenham recebido um bacharelato (B.Sc. - Bachelor of Science) antes de iniciarem seus estudos na área jurídica. Durante os quatro anos de bacharelato é fundamental que os candidatos tenham completado, com bom aproveitamento, cursos de Estatística e Matemática, além de outros cursos nas áreas de exatas, humanas, sociais e linguísticas. Isto garante que todos eles tenham um mínimo de familiaridade com o método das ciências. Esta familiaridade assegura, por sua vez, o viés realista dos aplicadores das leis locais como contraponto às posturas puramente idealistas na aplicação de leis ao convívio entre as pessoas e entre nações.

Talvez por influência da excessiva preocupação com uma formação fortemente erudita, entendida como independente da postura utilitarista de outras

\footnotetext{
8 “...E quando se juntam todas as disciplinas sociais na expressão - um tanto vaga - "ciência", é esse duplo sentido que devemos, na minha opinião, apresentar a distinção entre ciência descritiva ou explicativa e ciências normativas; distinção esta que não traduz senão uma diversidade de tendências, e que, para ser justo, necessita ser aplicada tanto com sobriedade quanto com flexibilidade". (tradução livre do autor) de GENY, Francois Science et technique en droit prive positif: nouvelle contribution a la critique de la methode 1922 [Fac. Direito] 340.13 G295s 1922 v. 1 DCV (Monografia).
} 
orientações epistemológicas, a história da educação jurídica brasileira deixou até recentemente, quando se avalia a dimensão dos períodos históricos, de exigir um mínimo de formação científica no segundo grau para prestigiar a chamada formação clássica. Felizmente esta alternativa de substituir o científico pelo clássico não existe mais para os novos juristas brasileiros. O eruditismo é um valor quase autônomo que, de forma independente de sua utilidade ou realismo, conferia, ou confere ainda, enorme prestígio ao jurista.

\section{Conclusão}

A utilização da denominação de Introdução à Ciência do Direito ao curso básico de iniciação aos estudos jurídicos não é apropriada. O Direito, por tratar do conhecimento normativo, não pode se limitar às regras do método das ciências em suas análises e proposições. Operadores do Direito precisam utilizar o método das ciências ao fazer análises sobre a eficácia e eficiência das normas quando implementadas de maneiras alternativas e precisam se familiarizar com ele para garantir que as proposições que venham a fazer ou utilizar tenham fundamentos na realidade do mundo. Por outro lado, assegurariam relevância maior à aplicação prática do Direito se suas análises estivessem igualmente baseadas em conhecimentos do mundo como ele é, objeto máximo das ciências.

Em vista das considerações feitas neste trabalho, a exigência de algum fundamento científico, mesmo que no nível do segundo grau educacional, deve ser visto como um avanço. Os argumentos aqui desenvolvidos sugerem que progressos maiores poderiam ser conseguidos na formação dos juristas do Brasil se de seus estudantes fosse requerido, no nível do terceiro grau, alguma familiaridade com o método das ciências. Isto poderia ser feito ampliando-se a grade curricular dos cursos jurídicos de modo a introduzir métodos das ciências e fundamentos de métodos estatísticos nos seus períodos iniciais ou de formação básica.

São Paulo, maio de 2013.

\section{Referências}

ARROW, K. Social choice and individual values. 2. ed. London: Yale University Press, 1963.

AZEVEDO, P. F. Introdução de Lon L Fuller. O caso dos exploradores de cavernas. Tradução e Introdução de Plauto Faraco de Azevedo. Porto Alegre: Sergio Antonio Fabris Editor, 1976. 
GENY, Francois. Science et technique en droit prive positif: nouvelle contribution a la critique de la methode. 1922 (Monografia).

PERELMAN, Chaim. De la justicia. Trad. de Ricardo Guerra. Pref. de Luis Recasens Siches. México: Unversidad Nacional Autónoma de México, 1964.

POSNER, R. A. The economics of justice. Cambridge: Harvard University Press, 1983.

STEHR, Nico. Knowledge Societies. London: Sage Publications, 1994. 